\title{
DOS CONCEPCIONES DE LA ÉTICA JUDICIAL *
}

\author{
Josep Aguiló Regla
}

RESUMEN. El trabajo trata de mostrar que hay una estrecha conexión entre las concepciones del Derecho y las concepciones de la ética judicial. En particular, se sostiene que las concepciones formalistas (y/o positivistas) del Derecho tienden a concebir la ética judicial como una ética diferenciada respecto de la ética general. Por el contrario, las concepciones postpositivistas del Derecho tienden a concebir la ética judicial como una ética aplicada.

Palabras clave: Ética judicial, Estado de Derecho, Estado Constitucional, concepciones del Derecho.

ABSTRACT. The paper tries to show that there is a narrow connection between conceptions of the law and conceptions of the judicial ethics. Especially, it supports that the formalist (and/or positivist) conceptions of the Law tend to conceive the judicial ethics as a differentiated ethics respect of the general ethics. On the contrary, the postpositivist conceptions of the law tend to conceive the judicial ethics as an applied ethics.

Keywords: Judicial ethics, Rule of Law, Constitutional State, conceptions of the Law.

* Fecha de recepción: 29 de junio de 2009. Fecha de aceptación: 30 de julio de 2009. 


\section{INTRODUCCIÓN}

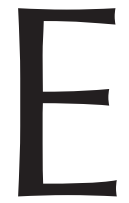

n la presentación al programa de unas jornadas sobre ética judicial celebradas en mayo de $2009^{1}$ podía leerse:

«El reconocimiento de que existen exigencias éticas para el juez no deja de ser una relativa novedad. En el esquema clásico positivista, entre el juez y la ley no hay nada que pueda desviar la vinculación directa de uno a otra. Sin embargo, en el Estado Constitucional de Derecho, en el que el Ordenamiento Jurídico incorpora los valores sustantivos proclamados en la Constitución, parece que no puede obviarse la reflexión sobre la ética judicial».

Este párrafo sugiere dos ideas a propósito de la ética ${ }^{2}$ judicial que, si bien son ciertas, tal vez requieren ser precisadas. La primera idea es que la explicación de la irrupción de la ética judicial en el mundo jurídico tiene que ver centralmente con las trasformaciones internas dentro del Estado de Derecho; básicamente con la transformación del Estado legislativo de Derecho en Estado constitucional de Derecho. Es obvio que algo (o mucho) de eso hay, pero, en mi opinión, no debe olvidarse que dicha irrupción se enmarca también en un fenómeno más general que trasciende con mucho el ámbito de lo jurídico. Me refiero al interés creciente por las «éticas profesionales». Piénsese, por ejemplo, en la irrupción de la ética de los negocios, de la ética periodística, de la ética de las profesiones médicas, de la ética de los científicos, etc. Todas ellas están adquiriendo una relevancia de la que probablemente han carecido durante largo tiempo. Parece, pues, haberse extendido la conciencia de que la «mera» bondad técnica (la bondad medios-fines, es decir, la eficiencia) junto con la «mera» permisión jurídica (la no-prohibición jurídica) no son suficientes para la justificación de las acciones y de las decisiones profesionales. El interés creciente por la ética judicial responde a transformaciones internas al Derecho pero está también en perfecta consonancia con un fenómeno más general de revalorización de las éticas profesionales ${ }^{3}$.

La segunda idea que el párrafo de la mencionada presentación sugiere es que la irrupción de la ética judicial tiene que ver con el hecho de que el orden jurídico del Estado constitucional al incorporar principios sustantivos de justicia habría hecho entrar en crisis la «vieja» tesis positivista de la separación conceptual entre el Derecho y la moral. Se sugiere que si en el Estado constitucional hay principios de justicia sustantivos que deben ser aplicados y cuya aplicación exige necesariamente llevar a cabo una deliberación de tipo moral, entonces la tesis positivista de la separación habría devenido simplemente insostenible y se habría abierto un espacio para la ética judicial que antes no existía. De nuevo, en mi opinión, algo (o mucho) de eso hay. Sin embargo, conviene introducir algún matiz importante. Gran parte del positivismo teórico no incorpora un ideal de regulación jurídica ni tampoco un ideal de juez y, en

${ }^{1}$ El presente texto reproduce con algunas modificaciones no sólo de detalle la ponencia presentada al curso «Ética judicial» que tuvo lugar los días 18, 19 y 20 de mayo de 2009 y que, bajo la coordinación del Sr. Magistrado D. Carlos Gómez, fue organizado por el Servicio de Formación Continua del Consejo General del Poder Judicial de España. biables.

2 En este trabajo voy a utilizar las palabras «ética» y «moral» como sinónimas y perfectamente intercam-

3 M. AtIENZA, «Ética judical», en Jueces para la democracia, núm. 40, 2001, pp. 17 y ss. 
consecuencia, no deja espacio alguno para hablar de ética «judicial». Una tesis central de este positivismo es la afirmación de que en el Derecho cabe distinguir entre casos regulados (resueltos por el sistema de reglas) y casos no regulados (no resueltos por el sistema de reglas). Pues bien, el positivismo teórico o metodológico vendría a sostener que en los casos regulados (resueltos por las reglas) la ética judicial resulta innecesaria porque el Derecho es suficiente para determinar el deber jurídico del juez; y en los casos no regulados la ética judicial es irrelevante en términos jurídicos porque se limita a expresar un ideal extrajurídico (ello es coherente con la tesis de la discrecionalidad del juez en sentido fuerte, libertad de elección). Distinta es la situación de lo que se ha convenido en llamar positivismo axiológico o ético porque, al igual que ocurre con las actitudes formalistas de muchos juristas prácticos, sí incorpora un ideal de regulación jurídica y un ideal de juez, dando lugar a hablar de ética judicial, de excelencia en la práctica judicial (y no sólo de desviación). Ello es muy importante y va a tener mucha presencia en este trabajo porque nos permitirá poner en conexión dos formas distintas de entender el Derecho - una positivista y/o formalista y otra no positivista y/o no formalista - con dos formas distintas de entender la ética judicial, la ética profesional del juez. La comprensión formalista del Derecho aparecerá conectada con una concepción de la ética judicial que la ve como una «ética diferenciada» de la ética general (tesis de la dualidad); y la comprensión no formalista del Derecho, con una concepción de la ética judicial que la ve como una «ética aplicada», como una aplicación de la ética general (tesis de la unidad) ${ }^{4}$. Ahora bien, no hay que dejarse engañar: una de las afirmaciones más reiteradas por los juristas formalistas (y por muchos positivistas) es la idea de que la ética judicial no es necesaria porque el Derecho es suficiente para determinar el deber del juez. En este sentido, la ponencia, lejos de aceptar esta afirmación, se propone mostrar que detrás de ella se esconde más bien una concepción inaceptable de «la ética judicial».

En esta ponencia voy a tratar de hacer lo siguiente. En primer lugar, bajo el título de «El poder del juez, el deber del juez y el Estado de Derecho», trataré de mostrar dos cosas. Una, que toda concepción no escéptica del Derecho es portadora en alguna medida de una concepción (más o menos explícita, más o menos consciente, más o menos rica) de la ética judicial o de la ética profesional del juez. Otra, que hay dos formas de concebir el Estado de Derecho, que son el resultado de poner el énfasis bien en el imperio de la ley, bien en la garantía de los derechos; es decir, una concepción más formalista y otra más sustantivista. A continuación, en el epígrafe titulado «El imperio de la ley, el modelo de las reglas y el ideal de juez», procuraré mostrar cómo la exacerbación de los «componentes formales» del Derecho comporta un ideal de regulación jurídica que lleva a concebir la ética judicial, la ética profesional del juez, como una «ética diferenciada» que «prohíbe» al juez abrir el razonamiento jurídico al razonamiento práctico general (a la moral). Seguidamente, bajo el título de «El Estado constitucional, el modelo de las reglas y los principios y el ideal de juez», trataré de mostrar cómo la incorporación de los principios sustantivos al Derecho comporta no

${ }^{4}$ Siempre que se abordan cuestiones relativas a la ética profesional aparece una pregunta fundamental: ¿cada profesión tiene su ética propia, distinta de la de las demás profesiones y distinta también de la ética ordinaria o común? La respuesta a esta pregunta traza la distinción entre dos concepciones enfrentadas de la ética profesional, que se concebirá bien como una «ética diferenciada», bien como una «ética aplicada». Sobre esta distinción volveré más adelante, pues va a jugar un importante papel en el desarrollo de este trabajo. 
sólo un cambio en la concepción del Derecho, sino también en la de la ética judicial, que no puede ser concebida ya como una «moral diferenciada», sino como una «moral aplicada». Finalmente, en «El deber jurídico del juez y el deber ético del juez», trataré de mostrar cómo, en un sistema jurídico justificado, el «deber ético del juez» no es nada distinto de «el sentido profundo del deber jurídico del juez» (es decir, no meramente convencional o superficial).

\section{EL PODER DEL JUEZ, EL DEBER DEL JUEZ Y EL ESTADO DE DERECHO}

El juez es la persona que ejerce la potestad jurisdiccional del Estado; y la potestad jurisdiccional del Estado consiste en aplicar el Derecho a los casos concretos resolviendo de manera definitiva las controversias relativas al cumplimiento de las normas jurídicas. Es evidente que esta definición de juez puede resultar parcial o insuficiente para muchos contextos y/o discursos jurídicos. Pero lo interesante de la misma es que, desde su simplicidad, caracteriza al juez como el titular de un poder del Estado. Construye la imagen del juez desde el poder, desde lo que le es posible hacer al juez y que nos resulta imposible hacer a todos los que no somos jueces 5 .

La importancia de lo anterior radica en que ninguna concepción del Derecho se ha mostrado escéptica hacia el poder de los jueces. Ninguna cree que su poder sea falso, ficticio o imaginario. Todas asumen que a los jueces les es posible producir resultados (realizar acciones tales como dictar sentencias, condenar, absolver, embargar bienes, ordenar alejamientos, etc.) que tienen gran impacto sobre los intereses de los afectados y que a los que no somos jueces nos resultan simplemente imposibles de producir. El poder de los jueces es, pues, un aspecto de la «realidad» del Derecho que es ineliminable y que a nadie le puede pasar inadvertido. Repito, ninguna concepción relevante del Derecho niega este dato de la realidad. De ahí, la extensión de la conciencia de la necesidad de controlar el poder de los jueces.

Sin embargo, sí hay (y ha habido) corrientes de pensamiento jurídico que se han mostrado escépticas hacia el Derecho. Es decir, que niegan (o dudan de) la capacidad de las normas jurídicas para guiar (regular) la conducta de los individuos, en general, y de los jueces, en particular; o que niegan que las normas jurídicas puedan suministrar razones para tomar decisiones relativas a su aplicación; o que consideran, por ejemplo, que el Derecho es radicalmente indeterminado y que, por tanto, nunca o casi nunca, suministra una única respuesta correcta; o que piensan que en la aplicación del Derecho, en realidad, no hay solución, sino pura y simple decisión; o que sostienen que las motivaciones (las argumentaciones) de las decisiones judiciales no son más que meras racionalizaciones a posteriori, en forma jurídica, que ocultan los verdaderos factores extrajurídicos que en realidad han provocado la decisión; etc. Desde cualquiera de estos parámetros,

${ }^{5}$ El análisis de la situación normativa de cualquier autoridad jurídica exige distinguir entre cuáles son los poderes normativos que tiene y cuáles son los deberes relativos al ejercicio de esos poderes. Es decir, exige distinguir entre «lo que le es posible hacer» a esa autoridad (qué resultados institucionales le es posible producir) y «lo que le está permitido hacer» (qué resultados institucionales producidos son correctos). En el caso de los jueces resulta evidente, por ejemplo, que les es posible dictar una «sentencia ilegal» aunque también lo es que no les está permitido hacerlo. Cfr. J. Aguiló Regla, Teoría general de las fuentes del Derecho, Barcelona, Ariel, 2000. 
es decir, desde los del escepticismo radical hacia el Derecho y hacia el método jurídico, si ya es difícil poder hablar de «deberes jurídicos de los jueces», mucho más complicado resulta todavía hablar de ética judicial. Ello es así por la sencilla razón de que, desde estos parámetros, la atribución de valor a la práctica de aplicar el Derecho sólo podrá provenir de ver en ella una oportunidad para proteger y/o promocionar bienes que son externos al propio Derecho y a su aplicación. Piénsese, por ejemplo, en las versiones fuertes del instrumentalismo jurídico, o en las corrientes del uso alternativo del Derecho o, más recientemente, en el movimiento de los Critical Legal Studies, etc. ${ }^{6}$. Podrá hablarse de «buen juez» pero en un sentido diferente, en el sentido del juez «político», del juez «ingeniero social», etc. En definitiva, si uno adopta una actitud fuertemente crítica y escéptica hacia el Derecho (hacia la capacidad del Derecho de guiar y controlar la conducta), entonces sólo se puede atribuir sentido y valor a la actividad del juez tomando en consideración bienes externos al propio Derecho. No es casualidad que todas estas concepciones se muestren escépticas también frente a (y/o tengan dificultades para construir) los principios de independencia y de imparcialidad de los jueces.

Hemos iniciado nuestro análisis partiendo de una definición de juez que pone el énfasis en el poder del juez (en lo que le es posible hacer al juez y que nos resulta imposible hacer a los que no somos jueces); $y$, a continuación, hemos apartado de nuestro horizonte a las concepciones fuertemente escépticas hacia el Derecho. Ahora, modifiquemos nuestra mirada sobre los jueces: tratemos de observarlos desde la perspectiva de su(s) deber(es) básicos. Esto supone mirar la jurisdicción no desde el poder, sino desde la función que el juez «debe» cumplir y desde las «garantías» para los ciudadanos de que, en efecto, el juez «cumple» esa función. Los procesalistas suelen distinguir entre lo que llaman garantías objetivas y garantías subjetivas de la jurisdicción. La garantía objetiva principal es la legalidad de la decisión; y ello, traducido a deberes del juez, implica el deber de tomar decisiones cuyo contenido sea una aplicación del Derecho preexistente. Las garantías subjetivas fundamentales son la independencia y la imparcialidad del juez; y ello, traducido en términos de deberes, conforma la peculiar manera de cumplimiento que el Derecho exige a los jueces. Independiente e imparcial es el juez que aplica el Derecho (actúa conforme al deber, en correspondencia con el deber, su conducta se adapta a lo prescrito) y que lo hace por las razones que el Derecho le suministra (motivado, movido por el deber). Por decirlo de manera breve, en el ideal del Estado de Derecho de un juez independiente e imparcial hay algo muy parecido a la exigencia kantiana para la conducta moral, pero referido al marco institucional del Derecho: que la explicación y la justificación de la conducta coincidan. El ideal de un juez independiente e imparcial designa a un juez que no tiene más motivos para decidir que el cumplimiento del deber. El cumplimiento del deber es tanto la explicación como la justificación de las decisiones que toma; o dicho de otra forma, los motivos por los que decide (la explicación de la decisión) coinciden con la motivación (la justificación) de la decisión ${ }^{7}$.

6 Sobre algunas de estas corrientes, vid. las obras de J. A. PÉREz LlEDÓ, El instrumentalismo jurídico en Estados Unidos, Lima-Bogotá, Palestra-Temis, 2008; El movimiento Critical Legal Studies, Madrid, Tecnos, 1996; y «Teorías críticas del Derecho», en F. LAPORTA y E. GARZÓN VALDÉs (coords.): El Derecho y la justicia, Madrid, Trotta, 1996.

7 En diversos trabajos me he ocupado extensamente de la interpretación de los principios de independencia y de imparcialidad de los jueces en términos de deberes de los jueces. En este sentido, vid. J. AguILÓ 
Obviamente, qué es una aplicación correcta del Derecho preexistente y qué exigen los principios de independencia y de imparcialidad no es algo que sea incontrovertido. Bien puede decirse que las diferentes concepciones no escépticas del Derecho construyen de maneras diferentes esas exigencias. Pero eso ahora no es lo interesante. Lo importante es darse cuenta de que en torno a estos tres deberes (el deber de aplicar el Derecho, el deber de independencia y el deber de imparcialidad) hay que construir lo que podríamos llamar los «bienes internos» relativos a la práctica de la jurisdicción, a la práctica profesional del juez. Ello es muy importante por lo siguiente. Si bien se considera, todos esos deberes pueden resultar controvertidos, pero no pueden ser negados. En el marco del Estado de Derecho, esos tres deberes son «necesarios», definitorios del rol de juez. Es decir, permiten definir el rol de juez esta vez no desde el poder, sino desde el deber. Quien ejerce la jurisdicción eludiendo el Derecho (esto es, no aplicándolo) o, por ejemplo, sometiéndose a personas o cumpliendo funciones de representación de grupos (es decir, no siendo independiente) o, por ejemplo, teniendo interés en el objeto de litigio (o sea, no siendo imparcial) bien puede decirse que «no es juez» o que «no ejerce de juez».

Esto último, que puede resultar un tanto «chocante», no es más que proyectar sobre la profesión de juez lo que siempre se dijo de las diferentes profesiones; que el profesional no puede disponer de los fines de su profesión, que hay en los mismos un componente respecto del cual sólo cabe adhesión (lo que, por cierto, permite construir el binomio profesión-vocación) ${ }^{8}$. Por ello, si se traicionan los fines de la profesión, entonces simplemente se deja de ser un profesional o de ejercer la profesión en cuestión. Por ejemplo, no hay nada de paradójico en decir que J. R. Mengele, el «médico» y criminal nazi que experimentaba con humanos en Auschwitz, no era un médico en el sentido no de que no tuviera la titulación necesaria, sino en el de que lo que hacía era incompatible con la práctica de la medicina o con el ejercicio de la profesión médica.

Naturalmente, no se trata aquí de enredarse con el uso de las palabras ni de determinar cuál es una buena definición de juez o de médico. Se trata de mostrar que cuando construimos el rol de juez no desde los poderes, sino desde los deberes, entonces vemos que hay deberes y fines que no son disponibles. Obviamente no son disponibles para el juez; pero, y esto es lo importante, no son disponibles en un sentido más profundo: en el Estado de Derecho el deber de aplicar el Derecho, el deber de independencia y el deber de imparcialidad son estrictamente indisponibles; es decir, son intrínsecos y necesarios al rol de juez. Veamos qué quiere decir eso.

Hace ya muchos años, en 1966, E. DíAz comenzaba su conocidísimo libro Estado de Derecho y sociedad democrática con un lapidario: «No todo Estado es un Estado de

REGLA, «Imparcialidad y aplicación de la ley», en Cuadernos de Derecho judicial (en prensa); «De nuevo sobre "Independencia e imparcialidad de los jueces y argumentación jurídica"», en Jueces para la democracia, núm. 46, marzo 2003, pp. 43 y ss.; e «Independencia e imparcialidad de los jueces y argumentación jurídica», en Isonomía, núm. 6, abril 1997, pp. 71 y ss.

8 En este sentido, el citadísimo párrafo de M. WEBER: «Es evidente que en la palabra alemana "profesión” (Beruf), como quizá más claramente aún en la inglesa calling, hay cuando menos una reminiscencia religiosa: la idea de una misión impuesta por Dios»; en M. WEBER, La ética protestante y el espíritu del capitalismo (trad. de L. Legaz LACAMBRA), Madrid, Sarpe, 1984, p. 85. En ocasiones, la palabra beruf es traducida directamente por vocación; piénsese, por ejemplo, en las conferencias del mismo WEBER, «La política como vocación» (Politik. als Beruf) o «La ciencia como vocación» (Wissenschaft als Beruf), M. WEBER, El político y el científico (trad. de F. Rubio Llorente), Madrid, Alianza, 7. ${ }^{\text {e ed., } 1981 .}$ 
Derecho» ${ }^{9}$. Esta frase pretendía cumplir múltiples funciones vinculadas al contexto político de la resistencia al franquismo; pero la frase en cuestión tiene también un sentido teórico que trasciende con mucho esa coyuntura. El concepto de «Estado de Derecho» no es sólo un concepto descriptivo-clasificatorio, es también - y de manera muy relevante- un concepto valorativo. Ello es importante por lo siguiente: El Estado de Derecho no nace de la simple juridicidad. Si así fuera, todo Estado moderno sería un Estado de Derecho, pues ningún Estado puede prescindir del Derecho como instrumento. Es, pues, un concepto normativo cuya función no es describir una mera propiedad del Derecho moderno. Es un concepto normativo/valorativo, resultado de la asunción de ciertas exigencias ético-políticas, que sirve para evaluar los diferentes sistemas jurídico-positivos ${ }^{10}$. El que sea un concepto con esta naturaleza es lo que permite entender por qué en torno a él se pueden desarrollar las actitudes crítico-prácticas propias del «aceptante» y formular un «ideal de regulación jurídica».

El Estado de Derecho no nace, pues, de la mera juridicidad, sino del compromiso con ciertas exigencias de tipo valorativo. De entre las múltiples exigencias que podrían enumerarse interesa ahora destacar las dos más importantes: una, el imperio de la ley y, otra, la garantía de los derechos fundamentales. El interés especial por ellas tiene que ver con dos cuestiones que van a aparecer a continuación. La primera es que ellas ilustran bien la tensión entre lo que A. Ross llamó «la conciencia jurídica formal» y «la conciencia jurídica material» en la administración de justicia ${ }^{11}$. La segunda es que el énfasis en una u otra propiedad del Estado de Derecho (el imperio de la ley o la garantía de los derechos) permite entender dos versiones distintas del mismo: La del Estado legal de Derecho, que gira en torno a la idea de imperio de la ley y al valor de la seguridad jurídica (condición de posibilidad y garantía de la libertad y de la autonomía de las personas); y la del Estado constitucional de Derecho, que gira en torno a la rigidez y a la normatividad de la constitución como garantía de los derechos fundamentales. A continuación voy a tratar de oponer dos modelos de «ideales de regulación» que grosso modo vienen a dar cuenta de estas tensiones internas al Estado de Derecho y a los que - como trataré de mostrar- cabe asociar dos formas distintas de entender y de concebir la ética judicial.

\section{EL IMPERIO DE LA LEY, EL MODELO DE LAS REGLAS Y EL JUEZ IDEAL}

El ideal de regulación jurídica vinculado a la versión del Estado de Derecho que pone el énfasis en el imperio de la ley presupone que el modelo adecuado para dar

9 E. Díaz, Estado de Derecho y sociedad democrática, Madrid, Taurus, 1998.

${ }^{10} C f r$. F. Laporta, «Imperio de la ley. Reflexiones sobre un punto de partida de Elías Díaz», en Doxa. Cuadernos de Filosofía del Derecho, núms. 15-16, vol. I, 1994, pp. 133 y ss. (http://www.cervantesvirtual.com/ portal/DOXA/index.shtml). A propósito del imperio de la ley, es imprescindible el libro también de F. LAPORTA, El imperio de la ley. Una visión actual, Madrid, Trotta, 2007.

11 Escribe Ross: «Puede decirse así que la administración de justicia es la resultante de un paralelogramo de fuerzas en el que los vectores dominantes son la conciencia jurídica formal y la conciencia jurídica material. La decisión a que se arriba está determinada por el efecto combinado de la interpretación cognoscitiva de la ley y de la actitud valorativa de la conciencia jurídica». A. Ross, Sobre el Derecho y la justicia (trad. de G. CARRIó), Buenos Aires, Eudeba, 2. ${ }^{a}$ ed., 1970, p. 134. 
cuenta de la estructura de un sistema jurídico es el modelo de las reglas. Por reglas hay que entender normas que correlacionan la descripción cerrada de un caso con una solución normativa. El ideal de regulación jurídica es el de la tipicidad, es decir, normas generales y cerradas cuya aplicación no exige (más bien excluye) cualquier forma de deliberación práctica o de valoración. Las normas abiertas son imperfecciones en la regulación cuya presencia en el sistema jurídico puede ser el resultado bien de una deficiente técnica legislativa (de un error), bien de una pura delegación (y/o abdicación) de poder normativo de los órganos creadores de normas (básicamente el legislador) hacia los órganos de aplicación (básicamente los jueces). Las normas abiertas, al exigir deliberación por parte de los destinatarios de las mismas, suponen siempre una desviación del ideal regulativo de la certeza jurídica, de la previsibilidad de las consecuencias jurídicas de las conductas.

Congruentemente con el modelo de las reglas, el arquetipo de razonamiento jurídico es el razonamiento subsuntivo. La justificación por subsunción consiste centralmente en mostrar que el caso concreto que se trata de resolver encaja (es subsumible) en el caso genérico descrito (regulado) por la regla. La subsunción (el encaje) de casos concretos en casos genéricos puede generar desajustes entre unos y otros. Si miramos el desajuste desde la perspectiva del caso concreto, entonces el desajuste se nos presenta como un problema de calificación (¿cómo se califican estos hechos?); y si lo miramos desde la perspectiva de la regla, del caso genérico, entonces el desajuste se nos presenta como un problema de interpretación (¿qué dice la regla?) ${ }^{12}$. Esto quiere decir que los desajustes entre casos y reglas (entre casos concretos y casos genéricos formulados por las reglas) son esencialmente de naturaleza semántica, de relación entre las palabras y sus significados, entre los términos y sus referencias. La lealtad a las reglas es, pues, lealtad a su expresión y a su significado; es decir, la lealtad a las reglas es una cuestión centralmente semántica, no valorativa.

Lo anterior desarrolla brevemente la idea citada en la Introducción a propósito de la presentación de unas jornadas sobre «ética judicial» en la que se leía que en el esquema clásico «entre el juez y la ley no hay nada que pueda desviar la vinculación directa de uno a otra», sugiriendo en cierto modo que no había espacio para la ética judicial. Sin embargo, la tesis que pretendo sostener aquí se opone drásticamente a esa sugerencia. La tesis es que si hay un ideal de regulación, entonces hay espacio para la ética judicial porque hay un ideal de juez. A efectos meramente persuasivos no me resisto a transcribir la argumentación del juez Keen en contra de algunos de sus colegas de tribunal a propósito del famoso - e imaginario - caso de los exploradores de cavernas ${ }^{13}$ :

«¿De dónde pues surgen todas las dificultades del caso y la necesidad de tantas páginas de discusión acerca de lo que debería ser tan obvio? Las dificultades, cualquiera

12 N. MACCORMIK distinguía cuatro tipos de casos difíciles. Dos afectaban a la premisa fáctica: problemas de prueba (¿qué ocurrió realmente?) y problemas de calificación (lo que ocurrió, ¿cómo se califica?). Y otros dos a la premisa normativa: problemas de interpretación (¿qué dice la norma?) y problemas de relevancia (¿hay norma aplicable?). Cfr. N. MACCORMICK, Legal Reasoning and Legal Theory, Oxford University Press, 2. ${ }^{a}$ ed., 1994. Para una exposición y crítica de la misma, vid. M. ATIENZA, Las razones del Derecho. Teorías de la argumentación jurídica, Madrid, CEC, 1991.

${ }_{13}$ L. L. Fuller, El caso de los exploradores de cavernas (trad. de G. CARRió y L. Nillus), Buenos Aires, Abeledo-Perrot, 2. ${ }^{a}$ ed., reimpresión (2008), pp. 49 y ss. 
sea la forma torturada bajo la cual aquél se presente, convergen todas hacia una fuente única, que es el fracaso en distinguir los aspectos jurídicos de los morales en este caso. Para decirlo lisa y llanamente, a mis colegas no les gusta el hecho de que la ley escrita exija la condena de estos acusados. A mí tampoco me gusta, pero a diferencia de mis colegas, yo respeto las obligaciones de un cargo que me exige descartar de mi mente las preferencias personales cuando me toca interpretar y aplicar la ley de este Commonwealth [...Mi colega Foster es uno de] los magistrados que aún no se ban acomodado al papel restringido que el nuevo orden les impone [...]. La afición de mi colega Foster por encontrar agujeros en las leyes me hace pensar en uno de los cuentos narrados por un autor antiguo acerca de un hombre que se comió un par de zapatos. Cuando se le preguntó si le había gustado, replicó que la parte que más le había agradado eran los agujeros. Así es como mi colega siente respecto de las leyes; cuantos más agujeros contienen más le agradan. En resumidas cuentas: no le gustan las leyes».

Este párrafo expresa bien lo que Ross llamó la tensión entre «conciencia jurídica formal» y la «conciencia jurídica material». El juez Keen es, podría decirse, la encarnación de la «conciencia jurídica formal» y el criticado juez Foster sería la encarnación de la «conciencia jurídica material». En cualquier caso, lo que me interesa mostrar es que no es cierto, aunque se ha afirmado muchas veces, que si uno adhiere a la concepción meramente formalista o cognitiva del ideal de regulación del imperio de la ley, entonces rechaza que haya espacio para la ética judicial. Ese espacio existe y, si bien se considera, es al que apela el juez Keen en su alegato. Lo que ocurre es que la ética judicial que cabe es una ética diferenciada, no una ética aplicada. Es una ética vinculada a una promesa y un cargo que no adopta (y/o aplica) los principios morales generales, sino que los cancela, deroga, exceptúa o inhibe. Es la llamada «tesis de la dualidad» respecto de las morales profesionales. En este sentido, y desde una perspectiva general, escribe E. GARZÓN VALDÉS:

«Llamaré a esta tesis "la tesis de la dualidad". Ella sostiene que hay que distinguir entre las llamadas 'morales profesionales' y la moral ordinaria. Aquéllas son morales adquiridas, es decir, los deberes que imponen son el resultado de alguna acción que el agente mismo ha realizado creando la obligación de someterse a ellos (una promesa, un contrato, la aceptación de una designación, por ejemplo). Mientras que la moral ordinaria respondería a las características básicas de todo ser humano, la moral profesional derivaría de las notas específicas de papeles sociales determinados y permitiría la realización de acciones que, desde el punto de vista de la moral ordinaria, estarían prohibidas» ${ }^{14}$.

El peso extraordinario que la conciencia jurídica formal ha jugado en la concepción del Estado de Derecho como imperio de la ley ha llevado a que se formulara un ideal de juez (y, en consecuencia, una ética judicial) cuya razón de ser ha sido la de impedir que el razonamiento judicial se abriera al razonamiento práctico general, se abriera a la moral. Es la ética judicial a la que apelaría el antes citado, e imaginario, juez Keen. Esta ética judicial (o ideal de juez o ética profesional del juez) es una ética diferenciada que observa con gran desconfianza a la ética general, a la moral ordinaria. Es más, aquélla se afirma por oposición y por temor a ésta. No en vano puede hablarse de algunos grandes miedos que la «conciencia jurídica formal» siente en relación con la moral ordinaria. A continuación me voy a referir a cuatro de estos grandes

14 E. GARZÓN VALDÉS, «Acerca de la tesis de la separación entre moral y política», en Derecho, ética y política, Madrid, CEC, 1993 , p. 567. En este mismo libro puede verse también el capítulo «Moral y política», pp. 541 y ss. 
miedos ${ }^{15}$. Respecto de cada uno de ellos voy a tratar de hacer lo siguiente: Tras poner nombre al miedo de que se trate, voy a intentar razonar como lo haría un juez que participara de estos planteamientos. Así, entre comillas, irá una glosa del miedo en cuestión y la formulación de algunas virtudes especialmente aptas para conjurar el supuesto peligro. No se trata tanto de una cuestión conceptual, cuanto de reconocer el arraigo de dichos miedos en nuestra cultura jurídica; es decir, reconocerlos como auténticos lugares comunes.

a) El miedo a la pérdida de la neutralidad valorativa. «Si realizo valoraciones — diría nuestro juez- entonces pierdo la neutralidad valorativa y abandono la actitud meramente cognitiva, que es la adecuada. El juez ideal no impone sus valoraciones, se limita a conocer: a conocer el Derecho, a conocer los hechos y a subsumir éstos en aquél. Incluso cuando la ley recurre a conceptos valorativos el juez no debe abandonar la referida actitud cognitiva ni imponer sus propias valoraciones ${ }^{16}$. Como es obvio, tampoco debe aficionarse — como diría el juez Keen— «a encontrar agujeros» en las leyes ni a realizar atribuciones de sentido (y/o de propósitos) a las mismas ${ }^{17}$. La tolerancia es, sin duda, una virtud esencial del juez ideal: está en la base de la inclinación de carácter hacia la neutralidad valorativa y de la aceptación de la ley democrática como la única forma civilizada de dirimir los conflictos valorativos» ${ }^{18}$.

b) El miedo al subjetivismo, a la pérdida de la objetividad. «Dado que la ética es una cuestión de sentimientos y de preferencias, si abro mi razonamiento jurídico a la moral, entonces impregno (contamino) mis decisiones jurídicas de subjetividad. Por tanto, dado que la moral es subjetiva y que el Derecho es objetivo, la templanza (la inclinación de carácter al autocontrol y a la inhibición de las propias emociones) es manifiestamente una virtud fundamental que debe adornar al juez excelente».

c) El miedo a la imposición de la moral como consecuencia de abrazar el relativismo. «En sociedades plurales y complejas donde conviven tantas y tan diferentes concepciones del bien y de la moral no tengo forma racional de dirimir las discre-

15 Esta relación de miedos podría extenderse sin dificultad. En realidad, está inspirada en los siete miedos que recoge M. DAVIS a propósito de la enseñanza de la ética profesional en general. Los siete miedos que menciona son los siguientes: a la pérdida de la neutralidad valorativa, a incurrir en subjetivismo, al relativismo, a que la ética profesional no se pueda enseñar en el aula, al claroscuro (Shades of Gray), al adoctrinamiento y a la afectación de virtud (the Fear of Holier-Than-Thou). Cfr. M. DAvis, Profession, Code and Ethics, Aldershot, Ashgate, 2002, pp. 234 y ss.

16 Un trabajo que refleja perfectamente estos planteamientos es P. E. NAVARRO, «La aplicación neutral de conceptos valorativos» (en Analisi e diritto, 2008). En él, siguiendo a C. AlCHOURRÓN y E. BulYGIN, sostiene que el uso y la aplicación de conceptos valorativos no implica realizar valoraciones, puesto que en la medida en que exista una convención pueden ser usados descriptivamente, y que, en consecuencia, cabe su aplicación neutral. Así, puede leerse: «[...] cuando un juez aplica un concepto valorativo no es necesario que use a ese predicado para imponer sus propias valoraciones en una determinada situación, sino que puede intentar determinar a qué cosas se refieren los miembros de su comunidad mediante esos conceptos».

17 En un sentido crítico similar escribe, por ejemplo, GUASTINI: «[... Se llama "laguna axiológica” a la falta no de una norma cualquiera, sino de una norma "justa", es decir, de una norma que no está pero que "debería” estar, porque es requerida por el sentido de justicia del intérprete o por una norma superior. El principio de igualdad, interpretado como principio de razonabilidad, es una fuente de lagunas axiológicas: podría decirse que es una máquina de producir lagunas [...]». R. GUASTINI, «La costituzione come limite alla legislazione», en Analisi e diritto, 1998, pp. 111 y 112.

18 En la cultura jurídica quien probablemente ha defendido mejor la conexión entre relativismo, democracia y tolerancia es KELSEN. En este sentido, vid. H. KELSEN, Esencia y valor de la democracia (trad. R. LuENGo TAPIA y L. Legaz LaCAmBRA), Barcelona, Guadarrama, 1977; y «Fundamentos filosóficos de la democracia», en J. RUIZ MANERO (ed.), Escritos sobre la democracia y el socialismo, Madrid, Debate, 1988. 
pancias valorativas. Frente a la soberbia de aquellos jueces que pretenden suplantar al legislador, hay que reivindicar la autorrestricción y la humildad ante la ley como virtudes judiciales; esto es, reivindicar el reconocimiento, por un lado, de los propios límites y, por otro, del valor que tiene la ley democrática en cuanto composición justificada de preferencias y de concepciones del bien que, en origen, son meramente relativas».

d) El miedo a los claroscuros. «La subsunción, que es la operación jurídica por excelencia, es binaria. Por el contrario, la valoración moral es vaga y gradual. Un caso particular encaja o no encaja en un caso genérico. Si hay vaguedad conceptual, entonces simplemente se ha delegado poder para decidir. Pero lo importante es darse cuenta de que en el carácter binario de las reglas está la principal fuente de seguridad para los ciudadanos, y la única oportunidad de someter a control el poder que ejercen los jueces. En consecuencia, el juez que no acepta la simplificación binaria de la realidad que supone la aplicación estricta de las reglas es, a diferencia de Keen, un juez autoritario (y antiliberal) que, por un lado, se mueve en una banda que va desde la "pura arbitrariedad" hasta el "perfeccionismo despótico" y que, por otro, resulta incompatible con la predicción de las decisiones judiciales».

Podríamos seguir con esta recreación pero probablemente no es necesario. Interesa, sin embargo, resaltar algunas cosas. Una, estos miedos recién expuestos están claramente arraigados en nuestra cultura jurídica y son fácilmente reconocibles por todos; constituyen, en este sentido, verdaderos lugares comunes. Otra, la exacerbación de la «conciencia jurídica formal» acaba generando un ideal de juez cuya principal función es la de aislar el razonamiento jurídico respecto del razonamiento moral general. Los deberes éticos del juez se ven, en consecuencia, no como una determinación o concreción de la moral general (como una moral aplicada), sino como una moral diferenciada que sólo adquiere pleno sentido por oposición a la moral general. El fundamento de la ética judicial así entendida no se halla, pues, en la ética general, sino en una promesa, en la lealtad a un cargo o algún otro aspecto de esta naturaleza. La ética judicial, la ética profesional del juez, vista de este modo opera como una excepción: «Algunos principios que valen para todos, no valen para el juez».

\section{EL ESTADO CONSTITUCIONAL, EL MODELO DE LAS REGLAS Y LOS PRINCIPIOS, Y EL JUEZ IDEAL}

El ideal de regulación jurídica vinculado a la versión del Estado de Derecho que pone el énfasis en la garantía de los derechos presupone que el modelo adecuado para dar cuenta de la estructura del sistema jurídico es el modelo de las reglas y los principios. Es decir, que en el Derecho además de reglas hay principios, hay normas que, al igual que las reglas, establecen una solución normativa (dicen lo que debe ser) pero que, a diferencia de ellas, no definen un caso (no indican cuándo son aplicables esas soluciones normativas). Los principios, así entendidos, son normas que dotan de sentido a las reglas. Permiten verlas, por un lado, como instrumentos para la protección y promoción de ciertos bienes (valores) jurídicos y, por otro, como resultados de un «balance, ponderación o compromiso» entre principios para el caso (genérico) que ellas regulan. Guiar la conducta y/o resolver casos mediante principios exige siempre 
deliberación práctica por parte de los sujetos normativos, de los destinatarios de las normas, no en vano se trata de normas abiertas.

En el Derecho hay reglas y, en consecuencia, hay razonamientos subsuntivos. Pero también hay principios; y guiarse por principios o aplicar principios exige un tipo de razonamiento, la ponderación, que es distinto del razonamiento subsuntivo, por cuanto desemboca en la formulación de una nueva regla que permita resolver el caso. Ahora bien, lo realmente significativo no es que existan estas dos operaciones o que se haya producido en el Estado constitucional un incremento cuantitativo de las ponderaciones en la aplicación del Derecho. Lo que supone un cambio fundamental es la consideración de que la ponderación de principios es una operación más básica que la subsunción. Las reglas no se entienden ya como meras manifestaciones de voluntad de la autoridad que las ha dictado, sino como el resultado de una ponderación de los principios relevantes llevada a cabo por dicha autoridad. Ello supone que la dimensión valorativa y justificativa del Derecho adquiere una relevancia fundamental ${ }^{19}$. El cambio central está, por tanto, en la consideración de que ser leal a las reglas no es serlo sólo a su expresión (porque no son sólo manifestaciones de voluntad), sino serlo también a sus razones subyacentes, al balance de principios que pretenden reflejar, a sus propósitos protectores y/o promocionales de derechos ${ }^{20}$. La lealtad a las reglas, y a su expresión, es un componente esencial de la lealtad al Derecho, pero en él no hay sólo reglas, también hay principios.

Todo ello implica que la «conciencia jurídica formal» juega su papel respecto del «discurso práctico general» ${ }^{21}$ pero que su función no puede ser la de encapsular el discurso jurídico y volverlo insular respecto del discurso moral porque - como diría NINO- las normas jurídicas no suministran razones autónomas; entre el Derecho y la moral hay una conexión justificativa ${ }^{22}$. Si — como se ha dicho- los principios son anteriores a las reglas, en el sentido de que la ponderación de principios es más básica y anterior a la promulgación de reglas, entonces ocurre que el Derecho «reconoce» acciones y estados de cosas como valiosos o disvaliosos, no los «crea» como tales. Este planteamiento supone un cambio radical respecto de los presupuestos del discurso jurídico y una alteración sustancial del ideal de excelencia del juez en relación con el modelo anterior ${ }^{23}$. Lo que desde aquella perspectiva se veía como riesgos y/o peligros

19 Sobre la distinción y las relaciones entre las operaciones argumentativas de la subsunción, la ponderación y la adecuación (medios-fines) vid. M. ATIENZA, El Derecho como argumentación, Barcelona, Ariel, 2006. Sobre la prioridad —en el sentido expuesto— de la ponderación sobre la subsunción, vid. «Presentación», en J. Aguiló Regla, M. Atienza y J. Ruiz Manero, Fragmentos de teoría de la constitución, Madrid, Iustel, 2007.

${ }^{20}$ En este sentido, el art. 40 del Código Iberoamericano de Ética Judicial establece que: «El juez debe sentirse vinculado no sólo por el texto de las normas vigentes, sino también por las razones en las que ellas se fundamentan». Sobre la relación entre reglas y razones subyacentes, vid. Á. RÓDENAS, «Entre la transparencia y la opacidad. Análisis del papel de las reglas en el razonamiento judicial», en Doxa. Cuadernos de Filosofía del Derecho, núm. 21, 1998.

${ }^{21} \mathrm{Vid}$., en este sentido, la tesis de AlEXY de que el discurso jurídico es un caso especial del discurso práctico general. Cfr. R. AleXY, Teoría de la argumentación jurídica: La teoría del discurso racional como teoría de la fundamentación jurídica (trad. M. ATIENZA e I. EsPejo), Madrid, CEC, 1989.

22 Vid. C. S. Nino, Fundamentos de Derecho constitucional, Buenos Aires, Astrea, 1992, pp. 70-74; y Derecho, Moral y Política. Una revisión de la teoría general del Derecho, Barcelona, Ariel, 1994, pp. 140-141. Una exposición del planteamiento de NINO se encuentra en V. RocA, Derecho y razonamiento práctico en Carlos $S$. Nino, Madrid, CEC, 2005, pp. 450-461.

${ }_{23}$ Entre otras cosas, porque, por ejemplo, la discrecionalidad no podrá ser más conceptualizada a la manera tradicional como una libertad en términos jurídicos; más bien deberá verse como un deber, como ese tipo especial de deberes que llamamos «responsabilidades». Sobre ello, vid. los trabajos de I. LIFANTE VIDAL, 
de la apertura del razonamiento jurídico al razonamiento moral y llevaba, por un lado, a formular un ideal de juez destinado a conjurar dichos riesgos y, por otro, a concebir la ética judicial como una ética diferenciada; desde aquí, se ve ahora como una mera expresión de prejuicios en relación con la moral de forma que, por un lado, el razonamiento jurídico deja de ser un razonamiento cerrado a la valoración moral y, por otro, la ética judicial deja de ser una ética diferenciada, para pasar a ser una ética aplicada. En consecuencia, «los principios que valen para todos, valen también para el juez» ${ }^{24}$. A continuación, pues, la réplica a cada uno de los miedos expuestos en el epígrafe anterior partiendo de que, en realidad, se trata más bien de «puros» prejuicios.

a) El prejuicio de la neutralidad valorativa. Aplicar el Derecho, desde esta nueva perspectiva, implica necesariamente hacer valoraciones. Incluso en la resolución de los llamados «casos fáciles» hay que hacer valoraciones. Un caso es fácil cuando la solución es el resultado de aplicar una regla del sistema y dicha solución es consistente (lógicamente compatible) con las otras reglas del sistema y coherente (valorativamente compatible) con los principios del sistema. Durante mucho tiempo, el prejuicio de la neutralidad valorativa ha llevado a la cultura jurídica a confundir la imparcialidad con la neutralidad. Además, cuando desde la perspectiva del «miedo a la moral» se apela a la tolerancia como virtud, se está confundiendo la tolerancia con la indiferencia; porque cualquier concepción aceptable de la tolerancia requiere una clara conciencia de sus límites (de lo intolerable).

b) El prejuicio del subjetivismo. En efecto, la ética tiene que ver con sentimientos, con intuiciones y con preferencias, pero no es sólo eso. Las reglas del discurso moral introducen controles que hacen que los consensos alcanzados tengan una dimensión de racionalidad. Para conjurar el prejuicio del subjetivismo es muy importante darse cuenta de que en el mundo de la moral (y, en general, de todas aquellas «realidades» que no son independientes de nuestras creencias) la intersubjetividad es el equivalente a la objetividad respecto del mundo empírico. Además, la apelación a la virtud de la templanza para conjurar el «miedo a la moral» confunde la templanza con la insensibilidad moral.

c) El prejuicio del relativismo. El prejuicio radica en dos puntos: uno, el énfasis puesto en la discrepancia valorativa, ya que no es cierto que desacordemos tanto ni tan intensamente; $\mathrm{y}$, dos, en la idea de que no hay posibilidad de dirimir discursivamente los desacuerdos valorativos. El consenso es un hecho tan observable como el disenso; y, en muchas ocasiones, enfatizar uno u otro no es el resultado de una observación más

«Dos conceptos de discrecionalidad jurídica», en Doxa. Cuadernos de Filosofía del Derecho, núm. 25, 2002, pp. 413-419, y «Poderes discrecionales», en A. García-FiguEROA (coord.), Racionalidad y Derecho, Madrid, CEC, 2006, pp. 107-131.

${ }_{24}$ Es posible que alguien tenga dificultades para ver el alcance de distinguir entre una concepción de la «ética profesional» como una «ética diferenciada» o como una «ética aplicada». Debe quedar claro que la idea de una ética aplicada no excluye en absoluto (y es perfectamente compatible con) la posibilidad de diferenciar deberes morales a partir de diferenciar roles. En este sentido, es obvio, por ejemplo, que los deberes morales del profesor y los deberes morales del estudiante no son los mismos; ahora bien, que los deberes no sean los mismos no significa que los principios últimos que los fundamentan sean distintos. Esto es muy importante porque implica que la justificación de la propia conducta no va dirigida exclusivamente a los que participan del mismo rol, sino a todos. Todos pueden participar discursivamente y opinar (es decir, ser interlocutores morales) respecto de los deberes relativos al ejercicio de una profesión. En definitiva, la «ética judicial» no es sólo un asunto de jueces vinculados por una promesa o un cargo, como tampoco la «ética médica» es sólo —ni mucho menos— un asunto de médicos «juramentados». 
minuciosa, sino de una pura decisión. El prejuicio del relativismo consiste precisamente en dar por probado lo que habría que probar: que el desacuerdo es muy superior al acuerdo y que, por tanto, no hay espacio para el discurso moral. Cuando desde la perspectiva del «miedo a la moral» se apela a la «autorrestricción» y a la «humildad ante la ley» se está, en realidad, confundiendo el «sometimiento al Derecho» (que, sin duda, es un deber judicial) con la irresponsabilidad moral del juez.

d) El prejuicio de los claroscuros. El prejuicio consiste en sostener que hay una incompatibilidad total entre el razonamiento clasificatorio (todo o nada) y el razonamiento valorativo (graduable); cuando en realidad no es así. Graduar, cuando se convierte en una operación mínimamente precisa, supone siempre tomar un punto 0 a partir del cual se puede realizar la graduación atribuyéndole un sentido. La existencia de ese punto 0 es lo que hace compatibles las dos formas de razonamiento, el clasificatorio y el gradual. Un ejemplo tal vez ayude a entender lo que se quiere decir: $\mathrm{Si}$ alguien emite un juicio de excelencia a propósito de la conducta y/o de la trayectoria de un juez, entonces cabe presuponer que ese alguien piensa, por un lado, que el juez en cuestión no incumplió sus deberes (razonamiento clasificatorio, todo o nada) y que, por otro, no se limitó a no incumplirlos, sino que hizo algo más en el sentido del cumplimiento (razonamiento graduable). En cualquier caso, desde la perspectiva del «miedo a la moral» tiende a confundirse el juez previsible (que permite la realización del valor certeza) con el juez ritualista (indiferente, insensible e irresponsable).

\section{EL DEBER JURÍDICO DEL JUEZ Y EL DEBER ÉTICO DEL JUEZ}

De todo lo dicho hasta aquí puede extraerse, me parece, una conclusión: Cualquiera que parta de una concepción general del Derecho no escéptica y que, además, considere que un determinado orden jurídico está justificado, entonces tiene que sostener que el deber ético del juez no es, en general, nada distinto de «el sentido profundo» del deber jurídico del juez. $\mathrm{O}$, dicho de otro modo, bajo estas condiciones el deber ético del juez no juega en contra de su deber jurídico, sino a favor del mismo por cuanto contribuye a conformarlo. De manera que los dilemas que pudieran surgir, en general, serían más aparentes (lo serían en primera lectura) que reales (no lo serían en lectura definitiva). Naturalmente, con ello no pretendo sostener que en nuestros órdenes jurídicos se ha realizado ya la justicia y que, por tanto, a un juez no se le pueden presentar cuestiones altamente problemáticas a propósito de la aplicación del Derecho en relación con un caso, ni nada por el estilo. La tesis es más simple: que hay una intimísima conexión entre la concepción del Derecho (qué es el Derecho, cuáles son sus límites y, sobre todo, de dónde procede su valor) y la concepción de la ética judicial; de forma que el deber ético del juez no es otra cosa que el cumplimiento, en grado de excelencia, de su deber jurídico. Si el valor del Derecho, su contribución civilizatoria, proviene precisamente de ser una superación de la moral, entonces la «ética judicial» (el ideal de excelencia judicial) se presenta como una «ética profesional» cuya finalidad central consiste en aislar (preservar) el razonamiento jurídico frente al razonamiento moral general. Por el contrario, si el valor del Derecho proviene de ser precisamente un instrumento necesario para la realización de la moral ordinaria, esto es, la institucionalización del discurso práctico general, entonces la «ética judicial» se ve como una 
«ética aplicada» cuya finalidad es, por un lado, garantizar la continuidad del instrumento Derecho (respetando y reforzando su institucionalización) y, por otro, preservar el sentido moral y crítico del Derecho mismo en su aplicación (evitando desviaciones meramente ritualistas $\mathrm{y} / \mathrm{o}$ formalistas).

En mi opinión, la segunda manera de enfrentar la cuestión es mucho más acertada y tiene un fundamento mucho mayor. Pero eso no es ahora y aquí lo importante. Lo que debe quedar claro es que para el pensamiento jurídico no escéptico (es decir, todo aquel pensamiento que es portador de un ideal de regulación) siempre hay espacio para la ética judicial, pues hay un ideal de juez. Si ello es así, entonces hay que denunciar como ideológica (falsa) la idea tan asentada en nuestra cultura jurídica $-\mathrm{y}$ que no es más que un mero producto de sus pulsiones formalistas- de que hay una oposición fuerte entre el deber ético del juez y el deber jurídico del juez; y que razonar y discutir en términos de ética judicial supone una fuga del Derecho. En realidad, lo que hay son dos concepciones del Derecho enfrentadas (una pretende encapsular al Derecho frente al discurso práctico general; y otra, sostiene que el discurso práctico general es el género al que pertenece el Derecho) que dan lugar a dos concepciones de la ética judicial también enfrentadas: una, como una ética diferenciada y, otra, como una ética aplicada. 